\title{
Primary Closure or Delayed Primary Closure? Assessment of Optimum Management of Surgical Wounds for Perforated Appendicitis
}

\author{
Muqdad Fuad*iD, Ahmed Modher(i) \\ Department of Surgery, FICMS, College of Medicine, University of Diyala, Baqubah, Iraq
}

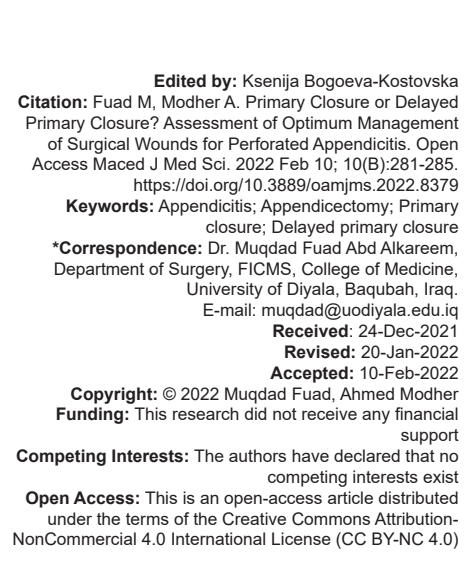

\section{Introduction}

Acute appendicitis is still the most common surgical problem facing the surgeon in the emergency room [1]. Approximately, 250,000 cases of appendicitis are registered annually in the united states [2]. The collective incidence is between 105 in the Eastern Europe and 151 in the Western Europe per 100.000 population a year with a peak incidence being between the ages of 10 and 30 years [3]. Perforation incidence varies between studies from $16 \%$ to $40 \%$, with a higher incidence seen in young age groups (40-57\%) and in those older than 50 years (55-70\%) [4].

Despite the routine use of broad-spectrum empirical antibiotics against the very predictable microorganisms in both complicated and uncomplicated appendicitis, still surgical site infection (SSI) is the most frequently observed postoperative morbidity in patients with perforated appendicitis reaching up to $25-50 \%$ in most of the reported series [5], [6], [7]. Postoperative wound infection is associated with prolonged postoperative pain, prolonged hospitalization and an added cost of extra health resources [8]. To primarily closure (PC) the wound or leaving it for delayed primary closure (DPC), is an important factor that affect the development of postoperative SSI infection. Leaving the wound open to be closed within 3-5 days (DPC) following appendectomy for perforated appendicitis is one policy aimed at decreasing SSI since the First World War [9].

Many studies recommend PC for incisions made for appendectomy of perforated appendicitis based on the availability of advanced well effective antimicrobials that can decrease the rate of SSI in such patients [10]. Chatwiriyacharoen (2002) and McGreal et al. (2002), both revealed that wounds of perforated or gangrenous appendicitis can be closed primarily most of the times [11], [12].

The idea of DPC is that it increases the blood flow and oxygen in the wound [13]. Also, a few days are allowed for the dirty wound to turn clean [10]. Delayed primary skin closure corresponds to a technique in which no special appliance is needed. It can be applied when 
contaminated or dirty wounds are present, allowing the tissues to drain their dirty fluids preventing build-up of microorganisms in a bound space before appropriate timing for skin closure reached [14]. However, many authors still prefer to perform a PC following good irrigation of the wound using $0.9 \% \mathrm{NS}$ and placement of subcutaneous drain [15]. Surgeons who challenge this approach (PC) have their philosophy of avoiding unnecessary increasing the length of hospital stay (LOS) and the added cost of medical resources [15].

The current study aimed to make a comparison between PC and DPC of infected wounds of open appendectomy for perforated appendicitis through a right lower quadrant incision with regard to the incidence of development of wound infection.

\section{Patients and Methods}

This is a cross-sectional study of 120 consecutive patients having perforated appendicitis underwent appendectomy. The study was conducted over 3 years (March 2017-March 2020) in Baquba Teaching Hospital/Diyala Province/Iraq. Perforated appendicitis cases that were enrolled in our study, comprised appendices that were grossly assigned to be perforated by the surgeon at the time of surgery. Appendices with microscopic perforation on pathological examinations weren't included in the study. Perioperative intravenous antimicrobials with aerobic and anaerobic coverage were prescribed for all patients until the temperature and white blood cell (WBC) count returned normal, then shifted to oral antibiotics. The antibiotics prescribed were cefotaxime and metronidazole in therapeutic doses as we are dealing with class four wounds (dirty-infected wounds). All patients underwent the classical appendicectomy via a Gridiron incision with burying of the appendicular stump. A swab for culture from the turbid ascetic fluid was obtained, and a peritoneal lavage using $0.9 \%$ saline was performed till clear effluence was gained followed by good gentle mopping. Soft tube drain inserted in the pelvis separately from the appendectomy incision. The layers of the abdominal wall (edges of the internal oblique muscle and external oblique aponeurosis) were approximated sequentially from within to without. The subcutaneous layer and the overlying skin were closed in patients dealt with by PC method; while they were left open in patients managed by DPC method. Depending upon the date of surgery, the enrolled patients were assigned to either PC or DPC management strategy following the odd and even dates. PC of the wound performed for patients with their surgeries performed on the odd dates, while DPC for surgeries performed on the even dates. Wounds of patients dealt with PC, were closed immediately at the end of the surgery using polypropylene. For DPC cases, the skin and subcutaneous tissue were left open and a gauze soaked with povidone-iodine placed in the wound and to be replaced twice daily to avoid too much accumulation of contaminated discharge. When the wound turned clean on the $5^{\text {th }}$ day post-operatively, it was closed using local anesthesia in the theater. When the wound still not clean, changing dressing continued and the DPC was postponed to the day when the wound become clean and ready to be closed. Wounds were considered to be infected when purulent discharge at the incision site present following closure regardless the bacterial culture, being positive or negative. In the two groups, infected wounds were reopened to be managed with frequent dressing, and a swab was obtained for culture and sensitivity. The surgical wounds were carefully watched and possibly opened if signs of wound infection as purulent discharge, increasing redness, induration, or warm incision site evolved.

Collected data were: age, gender, symptoms duration (time lasting from the commencement of symptoms to surgery), WBC count at admission time, LOS and if SSI evolve.

An associated medical comorbidities that might contribute to SSI were also recorded. Such conditions include diabetes, overweight $\left(\right.$ BMI > $\left.30 \mathrm{~kg} / \mathrm{m}^{2}\right)$, malnutrition which was diagnosed clinically by observing wasted muscles or with a serum albumin level $<25 \mathrm{~g} / \mathrm{l}$, use of steroid, and diseases related to the heart [16].

Patients who were immunocompromised as having malignancy, uremic or having chronic liver disease or liver cirrhosis were excluded from the study.

\section{Statistical analysis}

Chi-square and Fisher exact tests were applied to assess if there is any relation existed between the development of SSI and the method used to close the wound. Student t-test applied for mean comparisons (for continuous variables). A $p<0.05$ was regarded significant. The data were expressed as a mean \pm standard deviation, percentage forms, or as a frequencies.

\section{Results}

One hundred and twenty patients enrolled in our study. Sex distribution was 77 males and 43 females. Their mean age was 35.1 years (ranging 5-81 years). No patient was lost from the current study. No perioperative death or major morbidity as organ impairment, leak from the stump of the appendix or intraperitoneal collection was recorded. 
All of the 120 patients received the assigned method of wound managements, 61 in the PC group and 59 in the DPC group. The two groups were nearly comparable with no statistical differences with regard to the age and gender ( $\mathrm{p} 0.644$ and 0.663 respectively) (Table 1). The distribution of patients in the two groups with one or more risk factors (associated comorbidities) was also nearly equal (12 patients in DPC group vs. 10 in the PC group, $p$ 0.641). Furthermore, the study revealed no significant differences with regard to symptoms duration and WBC count between DPC group and $P C$ group (p 0.107 and 0.157 , respectively) (Table 1).

Table 1: Patient's demographic and clinical criteria

\begin{tabular}{llll}
\hline & DPC (No=59) & PC (No=61) & p-value \\
\hline Male: Female & $39: 20$ & $38: 23$ & 0.663 \\
Mean age (years) & $34.2 \pm 19.6$ & $35.9 \pm 21.6$ & 0.644 \\
SSI & $3(5.1 \%)$ & $20(32.8 \%)$ & 0.00029 \\
Associated comorbidities factors & & & \\
Patients with one or more comorbidity & $12(20.33 \%)$ & $10(16.39 \%)$ & 0.641 \\
Diabetes & 6 & 5 & \\
Malnourishment & 1 & 1 & \\
Use of corticosteroids & 0 & 0 & \\
Cardiovascular problems & 2 & 2 & \\
Over weight (BMl>30 kg/m $\left.{ }^{2}\right)$ & 3 & 2 & \\
Time from onset of symptoms to surgery (days) & $2.7 \pm 0.4$ & $2.3 \pm 0.3$ & 0.107 \\
White blood cell count $(\times 1000 / \mathrm{ul})$ & $16.7 \pm 1.1$ & $14.6 \pm 0.5$ & 0.157 \\
Length of hospital stay & $6.4 \pm 0.7$ & $8.3 \pm 0.9$ & 0.038 \\
\hline p $\leq 0.05$ (significant). & & &
\end{tabular}

In our study, a total of 23 out of 120 patients $(19.17 \%)$ developed SSI. The results of the infected wound cultures were Escherichia coli (58\%), then Bacteroides fragilis (29\%), and different Streptococci species (18\%). These bacteria were fitting those isolated in cultures from ascetic fluid during surgery (Table 2). Three wounds in the DPC group discharged pus 3 days after being closed. These wounds were opened and the discharge culture revealed $E$. coli, which was similar to the bacteria obtained from ascetic fluid during surgery. The remaining wounds were closely followed up for 14 days, no wound require reopening. Therefore, the rate of SSI in the DPC group was 3/59 (5.1\%) (Table 1).

Table 2: Types of organisms obtained by culturing intraperitoneal and the wound pus

\begin{tabular}{|c|c|c|c|c|}
\hline & \multicolumn{2}{|c|}{ Ascetic fluid $(\mathrm{No}=120)$} & \multicolumn{2}{|c|}{ Wound discharge $(\mathrm{No}=23)$} \\
\hline & DPC $(\mathrm{No}=59)$ & $P C(\mathrm{No}=61)$ & $\mathrm{DPC}(\mathrm{No}=3)$ & $\mathrm{PC}(\mathrm{No}=20)$ \\
\hline No growth & 5 & 5 & 0 & 2 \\
\hline Escherichia coli & 38 & 44 & 4 & 12 \\
\hline Bacteroides fragilis & 34 & 31 & 1 & 6 \\
\hline Streptococcal species & 17 & 12 & 0 & 4 \\
\hline Pseudomonas aeruginosa & 4 & 5 & 0 & 3 \\
\hline Clostridial species & 9 & 5 & 0 & 0 \\
\hline
\end{tabular}

Patients with their surgical incisions dealt with PC also observed for at least 2 weeks after operation. Wound infections were seen in 20 out of 61 patients $(32.8 \%)$. A significant correlation was found between the rate of occurrence of SSI and the strategy followed to close the wound (DPC 5.1\% vs. PC 32.8\%, p 0.00029).

Four out of the twenty patients who developed wound infection following closure in the PC group required readmissions. The LOS for each of these readmission was added to the past patient's one. None of the patients in the DPC group require readmission.
The LOS analyzed and it revealed significant difference between the two groups $(6.4 \pm 0.7$ days in DPC group vs. PC $8.3 \pm 0.9$ days, $p 0.038$ )

\section{Discussion}

Contaminated wounds that are left open for frequent dressing till being clean is an efficient policy that is followed for the last decenniums [17]. Meissner and Meisner mentioned the management of contaminated wounds for emergency abdominal surgeries by leaving them open for DPC since 1984 [18]. A great practice is earned by surgeons during the two world wars in dealing with contaminated wounds and applying DPC of such wounds after being healthy at day 3-7 following surgery was fixed [19]. Increasing the severity of the appendicitis being operated on leads to increase the rate of postoperative SSI following appendicectomy, and the majority of wound infections occurs following appendicectomy for complicated appendicitis [20]. The wounds of these dirty operations are essentially contaminated. Such contamination is the main factor that leads to the evolvement of the later SSI. The causative bacteria are essentially colonic flora [21].

Nowadays, many authors have published up to date guidelines for selecting the suitable prophylactic antibiotics when performing appendectomy [22]. The routine use of prophylactic antibiotics allows achieving PC of appendicectomy surgical incisions in spite of the data that suggest higher incidence of SSI in such contaminated wounds [23]. Giving perioperative antibiotics has been excessively attended by surgeons as this practice is associated with low incidence of infective complications. Furthermore, primarily close the surgical wounds allows omission of frequent dressing changes with its associated pain, reduce hospitalization, and reduces the total cost [23].

In our study, the rate of wound infection was $5.1 \%$ versus $32.8 \%$ for DPC and PC, respectively. Our results are nearly compatible to those by Ali et al., who revealed much higher rate of wound infection in the PC group than in the DPC one (36.67\% vs. $6.67 \%)$ respectively with $p<0.005$. In Ali et al. study, a total of sixty patients with perforated appendicitis were included, 30 patients were managed by PC and the other 30 were managed by DPC. Eleven patients out of thirty in the PC group and only two patients out of thirty in the DPC group developed wound infection [24]. In Ruey-An et al. study, a total of 70 patients with perforated appendicitis were randomly studied for the development of wound infection following primary and DPC. SSI occurred in $21.4 \%$ (15 patients). The incidence of SSI was higher for those managed by PC (38.9\% vs. $2.9 \%, p<0.001)$ [25]. Another study by Panhwar et al. in which sixty patients 
with perforated appendicitis were included. Twenty out of sixty patients $(33.3 \%)$ developed wound infection. No significant statistical difference was seen between PC group and DPC group (43.3\% and $23.3 \%-p=0.10)$, but a half decrease in the incidence of wound infection in the delayed primary group observed. May be a more number of patients need to be enrolled [26]. In Ahmad et al., A total of 158 patients with perforated appendicitis assigned into two groups (PC group and DPC group) each 79 patients. Thirty-six (22.8\%) patients developed wound infection. A significant association between the occurrence of wound infection and type of skin closure found $(6.3 \%$ in DPC vs. $39.2 \%$ in PC, $p<0.000)$ [27]. Managing the wounds using DPC decrease the number of colonic bacteria in the surgical wound, more precisely reducing anaerobic contamination of the wound [28]. However, DPC has the detriment of permitting Staphylococci bacteria to infect wounds of other patients before time to close the wound reached [19].

In our study, there was nearly equal sex distribution between DPC and PC group with $p=0.663$, which fit a study achieved by Siribumrungwong et al. who also found no difference with regard to the sex distribution with $p=0.42$ [14]. Also, in the current study, the mean age in those managed by DPC was 34.2 years while that for those dealt with $P C$ was 35.9 $p=0.644$. Such results are nearly compatible with study described by Chiang et al. [25], which found comparable mean age between the two groups (38.2 years for DPC group vs. 37.5 years for PC group). With regard to the duration of symptoms in the current study, it ranges from 1 to 3 days in both DPC and PC groups. In the study performed by Meka and Anasuri the mean duration of symptoms ranges from 1 to 4 days [29].

The current study revealed significant difference with regard to the total post-operative hospitalization length $(6.4 \pm 0.7$ days in DPC group vs. $8.3 \pm 0.9$ days in $\mathrm{PC}$ group $p=0.038)$. Such result does not agree those by Siribumrungwong et al. [14], who revealed no significant difference with regard to LOS between the two groups. But, it agrees with systematic review and meta-analysis by Tang et al. that revealed significant difference in the LOS between patients managed by DPC and those managed by PC; the mean difference was 0.39 and $p$ value of 0.0004 ) [30].

Our study revealed that the most common bacteria isolated from the wounds were E. coli $(58 \%)$, then B. fragilis (29\%), and different Streptococci species (18\%). Such results agrees results by Mostafa et al. [31] who also revealed that the commonest organisms obtained by culturing the infected surgical incisions were E. coli $(46.1 \%)$, then $B$. fragilis $(23 \%)$, and various Streptococci species (15\%).

The main limitations of the study was when applying the DPC because many patients frequently complain of the pain associated with the frequent change of dressing and the psychological upset of seeing the wound still open and the fears of the expected pain when the wound going to be closed under local anesthesia.

\section{Conclusion}

DPC is preferred policy over PC when managing an open appendicectomy wounds for perforated appendicitis, as the former is associated with low incidence of wound infection and shorter hospitalization.

\section{Recommendations}

It is recommended that wounds made for open appendicectomy for perforated appendicitis left open for frequent daily dressing using betadine or normal saline till the wound become clean and be ready for closure, usually within 3-5 days.

\section{References}

1. Ceresoli M, Zucchi A, Allievi N, Harbi A, Pisano M, Montori G et al. Acute appendicitis: Epidemiology, treatment and outcomesanalysis of 16544 consecutive cases. World J Gastrointest Surg. 2016;8(10):693-9. http://doi.org/10.4240/wjgs.v8.i10.693 PMid:27830041

2. Craig S. In: Brenner BE, Hardin E, Lober W, Talavera F, editors What is the Incidence of Appendicitis in the US? Medscape Gastroenterology; 2018. Available from: https://www.emedicine. medscape.com/article/773895-overview [Last accessed on 2018 Jul 23].

3. Ferris M, Quan S, Kaplan BS, Molodecky N, Ball CG, Chernoff GW, et al. The global incidence of appendicitis: A systematic review of population-based studies. Ann Surg. 2017;266(2):237-41. http://doi.org/10.1097/SLA.0000000000002188

PMid:28288060

4. Livingston EH, Woodward WA, Sarosi GA, Haley RW Disconnect between incidence of nonperforated and perforated appendicitis: Implications for pathophysiology and management. Ann Surg. 2007;245(6):886-92. http://doi.org/10.1097/01. sla.0000256391.05233.aa

PMid:17522514

5. Noorit P, Siribumrungwong B, Thakkinstian A. Clinical prediction score for superficial surgical site infection after appendectomy in adults with complicated appendicitis. World J Emerg Surg. 2018;13:23. http://doi.org/10.1186/s13017-018-0186-1 PMid:29946346

6. Siribumrungwong B, Srikuea K, Thakkinstian A. Comparison of superficial surgical site infection between delayed primary and primary wound closures in ruptured appendicitis. Asian J Surg. 2014;37(3):120-4. https://doi.org/10.1016/j.asjsur.2013.09.007 PMid:24238751

7. Ali K, Latif $\mathrm{H}$, Ahmad S. Frequency of wound infection in nonperforated appendicitis with use of single dose pre-operative antibiotics. J Ayub Med Coll Abbottabad. 2015;27(2):378-80. 


\section{PMid:26411121}

8. Badia JM, Casey AL, Petrosillo N, Hudson PM, Mitchell SA Crosby C. Impact of surgical site infection on healthcare costs and patient outcomes: A systematic review in six European countries. J Hosp Infect. 2017;96(1):1-15. http://doi. org/10.1016/j.jhin.2017.03.004

\section{PMid:28410761}

9. Hepburn $\mathrm{H}$. Delayed primary suture of wounds. $\mathrm{Br}$ Med J. 1919;1(3033):181-3. http://doi.org/10.1136/bmj.1.3033.181 PMid:20769371

10. Henry MC, Moss RL. Primary versus delayed wound closure in complicated appendicitis: An international systematic review and meta-analysis. Pediatr Surg Int. 2005;21(8):625-30. http:// doi.org/10.1007/s00383-005-1476-8

PMid:16044261

11. Chatwiriyacharoen W. Surgical wound infection post surgery in perforated appendicitis in children. J Med Assoc Thai. 2002;85(5):572-6.

PMid: 12188387

12. McGreal GT, Joy A, Manning B, Kelly JL, O'Donnell JA, Kirwan WW, et al. Antiseptic wick: Does it reduce the incidence of wound infection following appendectomy? World J Surg. 2002;26(5):631-4. http://doi.org/10.1007/s00268-001-0281-3 PMid:12098059

13. Childs DR, Murthy AS. Overview of wound healing and management. Surg Clin North Am. 2017;97(1):189-207. http:// doi.org/10.1016/j.suc.2016.08.013 PMid:27894427

14. Siribumrungwong $B$, Noorit $P$, Wilasrusmee $C$, Thakkinstian $A$. A systematic review and meta-analysis of randomised controlled trials of delayed primary wound closure in contaminated abdominal wounds. World J Emerg Surg. 2014;9(1):49. http:/ doi.org/10.1186/1749-7922-9-49

PMid:25221617

15. Siribumrungwong B, Chantip A, Noorit P, Wilasrusmee C, Ungpinitpong W, Chotiya $\mathrm{P}$, et al. Comparison of superficial surgical site infection between delayed primary versus primary wound closure in complicated appendicitis: A randomized controlled trial. Ann Surg. 2018;267(4):631-7. http://doi. org/10.1097/SLA.0000000000002464

PMid:28796014

16. Garcell HG, Arias AV, Sandoval CA, Sado AB, Serrano RN, García FG. Risk factors for surgical site infection after appendectomy for acute appendicitis; results of a crosssectional study carried out at a community hospital in Qatar (2013-2016). Hosp Pract Res. 2019;4(2):45-9. Available from: http://www.jhpr.ir/article_86003.html [Last accessed on 2021 Dec 20].

17. Cohn SM, Giannotti G, Ong AW, Varela JE, Shatz DV, McKenney MG, et al. Prospective randomized trial of two wound management strategies for dirty abdominal wounds. Ann Surg. 2001;233(3):409-13. http://doi. org/10.1097/00000658-200103000-00016

PMid: 11224630

18. Meissner K, Meisner G. Primary open wound management after emergency laparotomies for conditions associated with bacterial contamination: Reappraisal of a historical tradition. Am J Surg. 1984;148(5):613-7. http://doi. org/10.1016/0002-9610(84)90335-0

PMid:6388381

19. Stone HH, Hester TR Jr. Topical antibiotic and delayed primary closure in the management of contaminated surgical incisions. J Surg Res. 1972;12(2):70-6. http://doi. org/10.1016/0022-4804(72)90123-0

\section{PMid:4334929}

20. Koumu MI, Jawhari A, Alghamdi SA, Hejazi MS, Alturaif $A H$ Aldaqal SM. Surgical site infection post-appendectomy in a Tertiary Hospital, Jeddah, Saudi Arabia. Cureus. 2021;13(7):e16187. http://doi.org/10.7759/cureus.16187 PMid:34367794

21. Abdurrazzaaq A, Afuwape O, Ademola A, Fasina O. Bacterial pattern in acute appendicitis. Ann Afr Surg. 2018;15(1):8-13. Available from: https://www.ajol.info/index.php/aas/article/ view/170841 [Last accessed on 2021 Dec 20].

22. Sawyer RG, Claridge JA, Nathens AB, Rotstein OD, Duane TM, Evans $\mathrm{HL}$, et al. Trial of short-course antimicrobial therapy for intraabdominal infection. N Engl J Med. 2015;372(21):1996-2005. http://doi.org/10.1056/NEJMoa1411162

\section{PMid:25992746}

23. Amelia E, Arianto B, Purnamayanti A. The suitability and efficacy of perioperative antibiotics in relation with the surgical wound after appendectomy. Int J Pharma Med Biol Sci. 2016;5(4):1-5. Available from: http://www.ijpmbs.com/index. php? $\mathrm{m}=$ content $\& \mathrm{c}=$ index\&a=show $\&$ catid $=138 \& \mathrm{id}=222$ [Last accessed on 2021 Dec 20].

24. Ali MA, Asjad BZ, Perveen S, Nehal Z, Rajput BK. Primary closure versus delayed primary closure in perforated appendix: A comparative study. Pak J Surg. 2019;35(2):94-7. Available from: http://www.pjs.com.pk/journal_pdfs/apr_jun19/94.pdf [Last accessed on 2021 Dec 20].

25. Chiang RA, Chen SL, Tsai YC. Delayed primary closure versus primary closure for wound management in perforated appendicitis: A prospective randomized controlled trial. J Chin Med Assoc. 2012;75(4):156-9. http://doi.org/10.1016/j.jcma.2012.02.013 PMid:22541143

26. Panhwar W, Ghansham, Hyder Z, Ejaz S. Comparison of surgical site infection in complicated appendicitis: Primary versus delayed closure. J Surg Pak. 2018;23(2):1-4. Available from: http://www.old.jsp.org.pk/issues/jsp\%2023\%20(2)\%20 april\%20-\%20june\%202018/waryam\%20panhwar\%20oa.pdf [Last accessed on 2021 Dec 20].

27. Ahmad M, Ali K, Latif H, Naz S, Said K. Comparison of primary wound closure with delayed primary closure in perforated appendicitis. J Ayub Med Coll Abbottabad. 2014;26(2):153-7. PMid:25603666

28. Pettigrew R. Delayed primary wound closure in gangrenous and perforated appendicitis. Br J Surg. 1981;68(9):635-8. http://doi. org/10.1002/bjs. 1800680910 PMid:7023599

29. Meka M, Anasuri B. Comparison of superficial site infection between delayed primary and primary wound closures in ruptured appendicitis. Int Surg J. 2018;5(4):1354. http://doi. org/10.18203/2349-2902.isj20181109

30. Tang S, Hu W, Hu L, Zhou J. Primary versus delayed primary incision closure in contaminated abdominal surgery: A metaanalysis. J Surg Res. 2019;239:22-30. http://doi.org/10.1016/j. jss.2019.01.047

PMid:30782543

31. Mostafa A, Borai MI, Ghanema MK. Comparison of Superficia surgical site infection between delayed primary versus primary wound closure in complicated appendicitis. Med J Cairo Univ. 2020;88(3):1257-64. http://doi.org/10.21608/ MJCU.2020.110877 